\title{
Estado atual da conservação do patrimônio escultórico no Brasil
}

\author{
Beatriz Coelho
}

\begin{abstract}
Resumo: Visão panorâmica do patrimônio escultórico religioso no Brasil, principais escultores conhecidos, materiais e técnicas empregados. Os pioneiros da preservação, restauração e da formação dos restauradores no país. A formação nas universidades. Critérios adotados ontem e hoje. O papel da Associação Brasileira de Conservadores e Restauradores de Bens Culturais, Abracor. O Centro de Conservação e Restauração de Bens Culturais da Universidade Federal de Minas Gerais (Cecor). A criação e atividades do Centro de Estudos da Imaginária Brasileira, (Ceib), e seu papel na ampliação do conhecimento e no intercâmbio entre os pesquisadores e os que atuam nesse campo das artes plásticas, e do patrimônio tão expressivo e tão importante do nosso país.
\end{abstract}

Palavras chave: Brasil, escultura policromada, imagens devocionais, formação de restauradores, associações, Intervenções, critérios mais adotados.

\section{Estado actual de la conservación del patrimônio escultórico en Brasil}

Resumen: Visión panorámica del património escultórico religioso en Brasil, principales escultores conocidos, materiales y técnicas empleados. Los pioneros de la preservación, restauración y de la formación de los restauradores en el país. La formación en las universidades. Los criterios adoptados ayer y hoy. El papel de la Asociación Brasileña de Conservadores y Restauradores de Bienes Culturales, Abracor. El Centro de Conservación y Restauración de Bienes Culturales de la Universidad Federal de Minas Gerais (Cecor). La creación y actividades del Centro de Estudios de la Escultura Devocional Brasileña (Ceib), su papel en el aumento del conocimiento y en el intercambio entre los investigadores y los que actúan en ese campo de las artes plásticas, y del patrimonio tan expresivo y tan importante en nuestro país.

Palabras clave: Brasil, escultura policromada, imágenes de devoción, formación de los restauradores, asociaciones, intervenciones, critérios adoptados.

\section{Current state on the conservation of sculpture heritage in Brazil}

Abstract: Panoramic vision of religious sculpture in Brazil, foremost sculptors, materials and techniques employed. Pioneers of preservation, restoration, and of the conservation training in the country. University degree programs. Criteria adopted in the past and in the present. The role of the Brazilian Association of Conservators and Restorers of Cultural Heritage, Abracor. The Center for the Conservation of Cultural Heritage of the Federal University of Minas Gerais (Cecor). The foundation and activities of the Center of Brazilian Religious Sculpture Studies, Ceib, and its role in the expansion of knowledge and exchange among those who research or create plastic art, a field of such expression and of such importance in our country.

Keywords: Brazil, polychrome sculpture, religious sculpture, education of restorers, associations, conservation, criteria adopted.

\section{Introdução: A escultura devocional no Brasil}

A história da escultura religiosa no Brasil teve início logo após a chegada dos portugueses e o princípio da colonização. Pouco tempo depois do descobrimento, vieram frades franciscanos, carmelitas, beneditinos, dominicanos e jesuítas, com o objetivo de evangelizar os índios e trazendo consigo imagens devocionais. Não há muitos estudos sobre as primeiras imagens, que foram levadas para locais no litoral, onde hoje ficam os estados da Bahia, Pernambuco, Rio de Janeiro e São Paulo. Segundo Myriam Andrade Ribeiro de Oliveira, ainda são conservadas, desses primeiros tempos: a Nossa Senhora das Maravilhas, doada por Dom João III em 1550 à recém fundada cidade de Salvador, e a Nossa Senhora de Guadalupe, ambas 
conservadas no Museu de Arte Sacra da Universidade Federal da Bahia (Oliveira 2000: 47). Também do século XVI é a Nossa Senhora da Penha, da cidade de Vila Velha, no estado do Espírito Santo, trazida por frei Pedro Palácios, franciscano de origem espanhola, provavelmente em 1570 (Colnago Filho 2007:1-5).

A imaginária religiosa dos séculos XVII e XVIII no Brasil reflete alguns dos aspectos mais originais e criativos do patrimônio cultural brasileiro desse período. Suas principais funções eram a veneração nos altares, o uso em procissões e outros rituais católicos, e em oratórios, para a devoção doméstica. Podem ser enquadradas em três períodos estilísticos distintos: uma fase maneirista, durante todo o século XVII, quando predominavam as oficinas conventuais; um período barroco propriamente dito, entre 1720 e 1770 , e, finalmente, uma fase rococó, nas três décadas finais do século, com prolongamento no século XIX em algumas regiões (Oliveira 2000).

Os artistas do século XVII mais conhecidos são os beneditinos: frei Agostinho da Piedade, frei Agostinho de Jesus e frei Domingos da Conceição da Silva, graças aos estudos feitos pelo também beneditino Dom Clemente da Silva-Nigra. Frei Agostinho da Piedade (1580-1661), de origem portuguesa, viveu e trabalhou na Bahia; frei Agostinho de Jesus (1610-1661), discípulo de frei Agostinho da Piedade, era brasileiro, de São Paulo, e frei Domingos (1643-1718) era de Matosinhos, litoral norte de Portugal (Silva-Nigra 1950).

Frei Agostinho da Piedade trabalhou somente em barro e fez inscrições e datou quatro imagens, o que facilitou os estudos comparativos de Silva-Nigra para atribuir a ele outras esculturas. Foram elas: Nossa Senhora de Montesserate (86cm de altura, policromada, 1636); Sant'Ana Mestra (77cm de altura, policromada, com inscrição: “1642-frei Agostinho"); Menino Jesus de Olinda1 [figura 1 e 2] (40cm), escultura na qual Dom Clemente encontrou três gravações diferentes, uma com "a sigla" do autor , outra "frei Agostinho. Religioso de São Bento", e a terceira "Parce mihi domine")2; e, ainda, a imagem de Santa Catarina de Alexandria (49 cm, inscrição: "fr. Agostinho"). Deste frade artista ainda existem 14 bustos relicários representando diversos santos mártires e o mesmo número de imagens de vulto, hoje sem policromia (Silva-Nigra 1971).

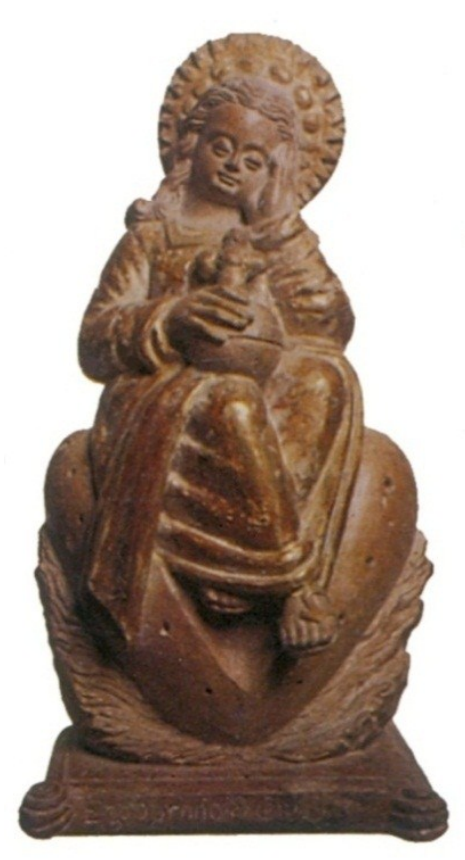

Figura 1. Menino Jesus de Olinda. Frei Agostinho da Piedade. Barro cozido, C. 1640, 40 cm. Mosteiro de São Bento, Olinda - Pernambuco. Foto: Beatriz Coelho

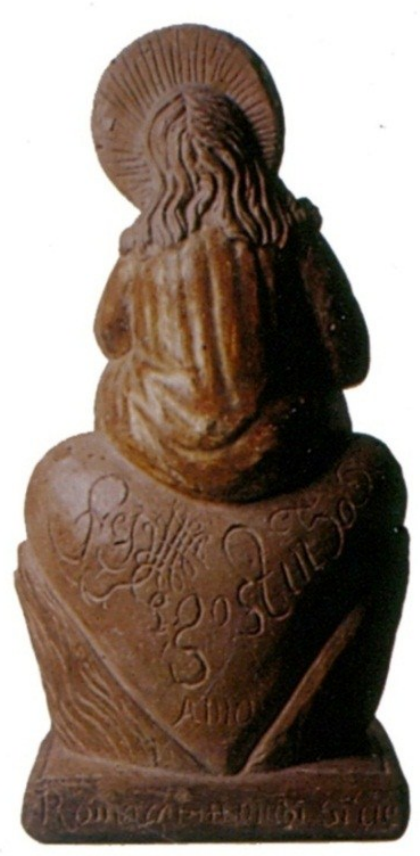

Figura 2. Menino Jesus de Olinda. Frei Agostinho da Piedade. Inscrições. Foto: Beatriz Coelho. 
Em São Paulo, na mesma época, frei Agostinho de Jesus também criou imagens em barro, depois cozido e policromado, especialmente da Virgem Maria em suas diversas invocações, como Nossa Senhora da Conceição e do Rosário, santos beneditinos, mártires e santas virgens. A policromia dessas imagens era feita diretamente sobre o suporte de barro, sem preparação nem bolo armênio.

Frei Domingos da Conceição da Silva fez os votos de irmão leigo no Mosteiro de São Bento do Rio de Janeiro, com 47 anos, em abril de 1691 (Souza 2007). Executou, neste monumento, toda a talha da capelamor, do frontispício até o arco cruzeiro, o Cristo do coro, Nossa Senhora do Montesserrate, São Bento e Santa Escolástica ${ }^{3}$ Santo Amaro, que fica na igreja e duas imagens do Senhor crucificado que estão no mosteiro de Pernambuco. ${ }^{4}$

Outra ordem religiosa ligada à confecção de imagens devocionais é dos jesuítas, que ensinavam aos índios a religião católica e a confecção de imagens, na área conhecida como das Missões, na região do Rio da Prata, da qual faziam parte o Brasil, a Argentina e o Paraguai. São conservadas, no Brasil, perto de 100 imagens dessa região, principalmente no Museu das Missões. Elas representam várias invocações da Virgem Maria, Anjos, São Lourenço, São Francisco de Borja, Santo Isidro e santos da ordem jesuíta, como São Estanislau Kostka, São Luís de Gonzaga e São Francisco Xavier. Algumas têm policromia simples, diretamente sobre o suporte de madeira, e muitas são de grandes dimensões, como o São Lourenço com relevos e sem policromia, com $220 \mathrm{~cm}$ de altura (Missões, Margs 2000: 61).

Iniciadas com as ordens religiosas, as esculturas começaram a ser feitas por leigos, na Bahia, Pernambuco, São Paulo, Rio de Janeiro. O suporte mais empregado nas esculturas devocionais do século XVII foi o barro, que permitia bons resultados sem muita complexidade de técnica e instrumental. As peças eram em barro cozido, ocas (por necessidade da técnica) e com a policromia bem simplificada, feita diretamente sobre o suporte após a queima. O douramento, quando existente era, geralmente, colocado apenas nas bordas de algumas vestimentas.

No século XVIII, os artistas leigos dominavam a produção de imagens, e escolas regionais se diversificavam, sendo particularmente características as de Pernambuco [figura 3], Bahia, Minas Gerais e Maranhão (Oliveira 2000). O barro continuava a ser empregado, especialmente em obras de sabor popular, porém a madeira passou a ser o material mais utilizado em todo o Brasil, sendo a mais empregada a Cedrella, uma meliácea que existia em abundância em várias regiões do país, conhecida popularmente como cedro (Coelho 2005). A maioria das imagens foi executada em madeira maciça, mas há também esculturas ocas em grande quantidade. Em pesquisas realizadas em Minas Gerais entre 1990 e 1996, verificamos, em muitas esculturas, uma diminuição da riqueza de detalhes a partir da lateral das figuras, certamente por serem esculturas que seriam colocadas em nichos nos altares. O ouro, que revestia totalmente as imagens na parte da frente do estofamento, deixa de existir nas costas ou é utilizado como reservas. As punções e a pintura a pincel também são menos executadas nas costas dos personagens. Encontramos na Basílica de Bom Jesus de Matosinhos, em Congonhas do Campo, e no Museu da Inconfidência, de Ouro Preto, anjos tocheiros de grande porte sem nenhuma policromia na parte posterior, deixados apenas na preparação. Há, não só em Minas, mas em todo o Brasil, muitas imagens de vestir articuladas, principalmente as que saem em procissão na Semana Santa. Algumas com anatomia simplificada e algum detalhe de vestimentas, e outras com a cabeça, mãos e pés bem entalhados e policromados, mas com a parte inferior feita apenas com ripas de madeira. Para Maria Regina Emery Quites (2006), essas seriam as imagens de roca propriamente ditas, uma subdivisão das imagens de vestir. As vestes são, até hoje, trocadas por novas em cada festa comemorativa. Algumas vestes ou mantos em tecido eram utilizados mesmo em imagens de vulto e policromadas. Lamentavelmente, no nosso país não se tem o hábito de preservar essas vestimentas antigas.

Com a descoberta do ouro em Minas Gerais, entre 1690 e 1695, afluíram para a região centenas de portugueses, paulistas e baianos. Ao colonizarem essa área, os portugueses traziam consigo suas imagens de devoção, criando outras e ensinando aos brasileiros a arte da escultura e da execução de retábulos. Ainda há muito a ser estudado em relação à criação e autorias das esculturas devocionais desses primeiros tempos do Brasil. O que torna muito difícil esses estudos é que a escultura (como a pintura e as obras de 
talha) era feita por profissionais conhecidos como "oficiais mecânicos e artífices", que não assinavam seus trabalhos e, algumas vezes, não podiam, nem sabiam, assinar recibos. Hoje muitos nomes são conhecidos (embora os trabalhos nem sempre sejam identificados) pelas pesquisas em arquivos e transcrições de documentos originais publicados por Marieta Alves (Bahia), Judith Martins (Minas Gerais) e, mais recentemente, Vera Acioli (Pernambuco).

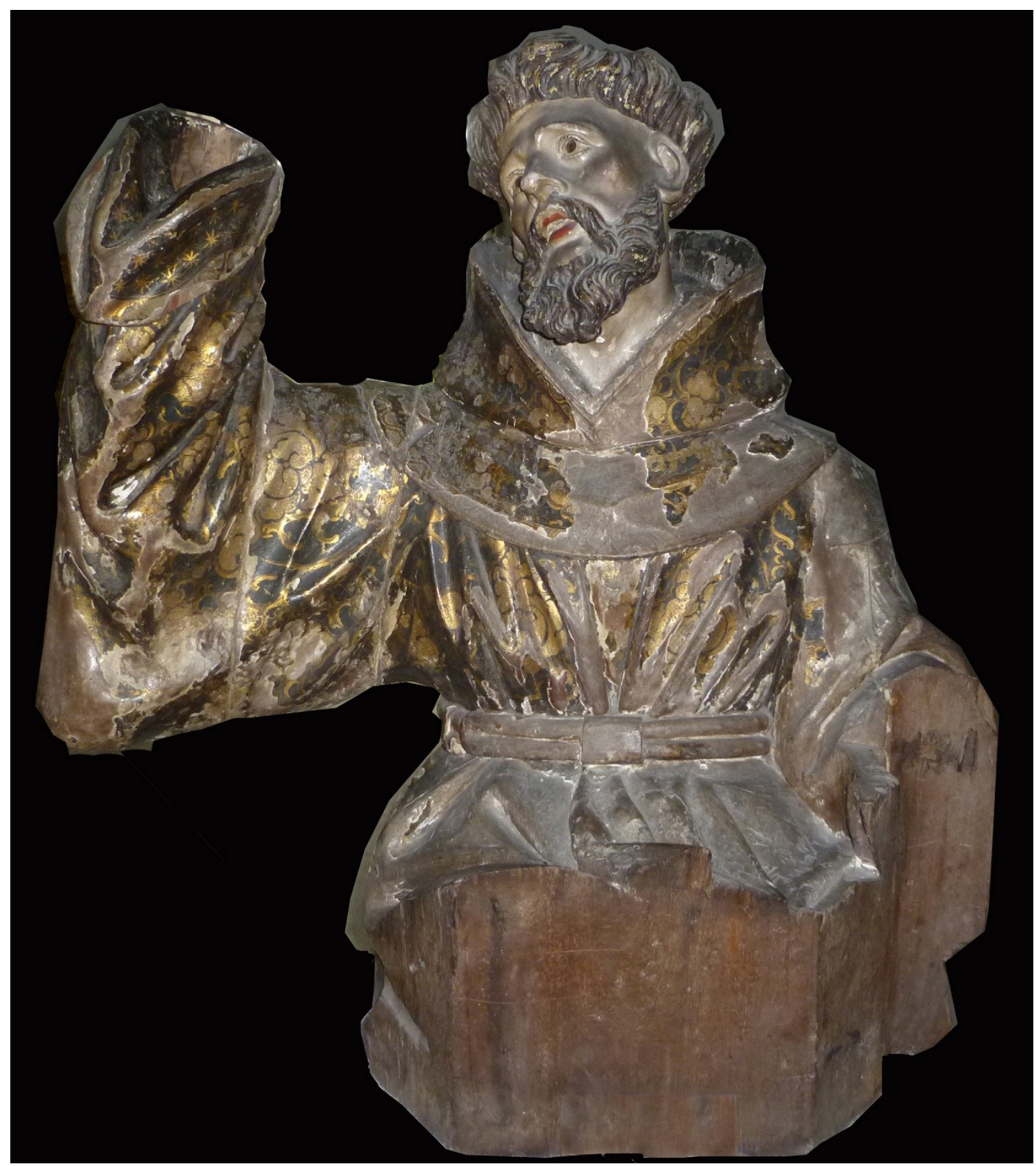

Figura 3. São Francisco de Assis. Madeira dourada e policromada. cm Ordem Terceira de São Francisco, Recife - Pernambuco. Foto: Beatriz Coelho. 
Entre 1720 e 1723, portanto pouco depois da descoberta das minas de ouro, foi proibida pela coroa portuguesa a instalação de qualquer ordem primeira religiosa em Minas Gerais, tornando-se, por isso, as ordens terceiras, de leigos (Santíssimo Sacramento, Rosário, São Miguel e Almas, São Francisco, Carmo, Mercês), as principais encomendantes de objetos sacros e imagens devocionais. O estofamento das imagens com folhas de ouro passa a ser muito usado, não apenas em Minas, mas também na Bahia, Sergipe, Rio de Janeiro, Pará, Maranhão, Pernambuco, Paraíba e Alagoas. Foram empregados também outros materiais e técnicas, como olhos de vidro, esgrafitos, punções, relevos, folhas de prata, aplicações de rendas douradas, pedras e até perucas, no caso de imagens de vestir, sempre buscando dar um maior naturalismo às imagens. No século XVIII, e em todo o período colonial, o mais importante escultor do Brasil foi Antônio Francisco Lisboa, o Aleijadinho (1738-1811), que trabalhou em arquitetura, retábulos e imagens, sendo o conjunto de sua obra de extraordinária qualidade, havendo sobre ele muitos livros publicados (Bazin 1984; Oliveira 2005).

Ainda em Minas, temos obras dos portugueses, Francisco Xavier de Brito (? -1751) e Francisco Vieira Servas (1720-1811) [figura 4], além dos mestres mineiros, de Piranga, [figura 5] de Barão de Cocais, de Sabará, de Lagoa Dourada e de Vitoriano Veloso, e outros ainda a serem identificados e estudados. Na Bahia, distinguiu-se Manoel Inácio de Costa (1763-1857) e Francisco das Chagas (não se conhecem as datas de seu nascimento e morte), e, em Pernambuco, Manoel da Silva Amorim (1793-1873), com obras já no século XIX. Em Goiás, nasceu e trabalhou no século XIX, esculpindo e policromando imagens com características do século XVIII, José Joaquim da Veiga Valle (1806-1874) (Salgueiro, 1983).

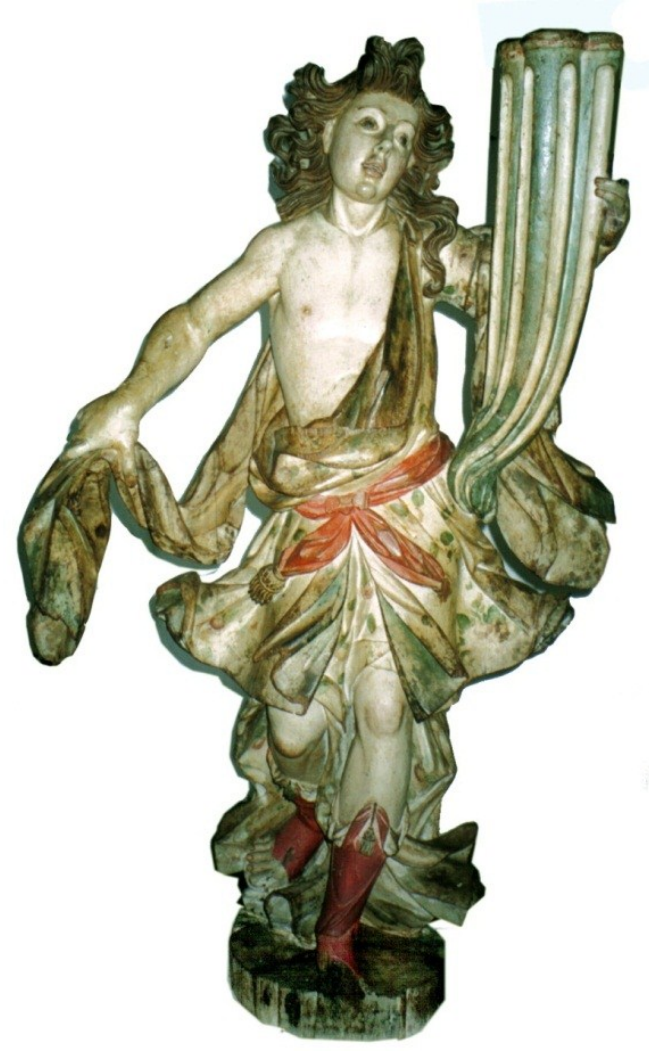

Figura 4. Anjo tocheiro. Francisco Vieira Servas (Atribuição). Madeira policromada, $105 \mathrm{~cm}$, Século XVIII. Museu da Inconfidência, Ouro Preto - Minas Gerais. Foto: Beatriz Coelho.

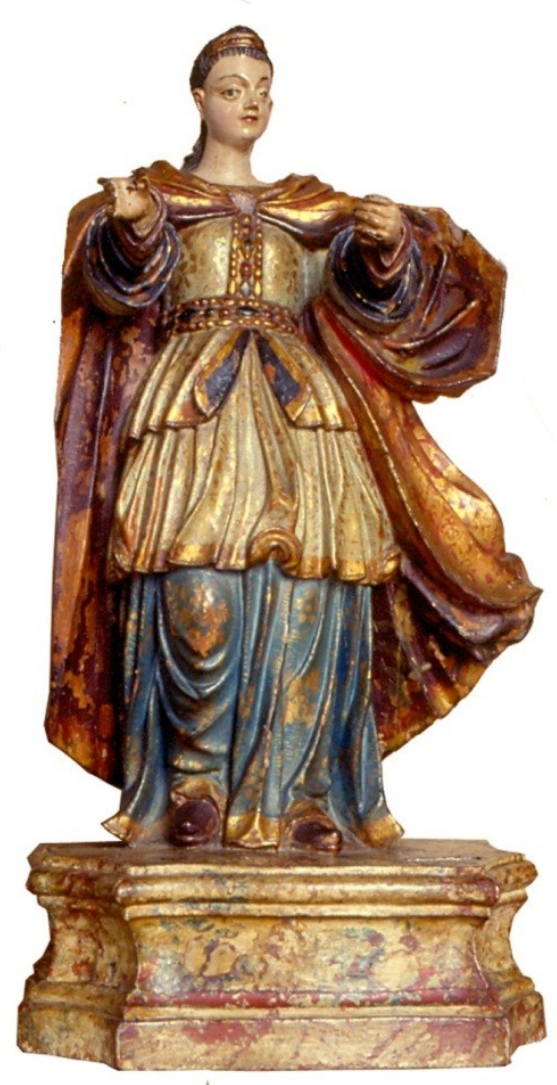

Figura 5. Santa Bárbara. Mestre Piranga (Atribuição). Madeira dourada e policromada. $62 \mathrm{~cm}$ Museu da Inconfidência, Ouro Preto, Minas Gerais. Foto: Beatriz Coelho. 
No século XIX volta a ser muito utilizado em São Paulo o suporte de barro, em imagens de tamanho pequeno, variando de 15 a $70 \mathrm{~cm}$, ocas e conhecidas como Paulistinhas, e as imagens em miniaturas, sem policromia, usadas pelos escravos, feitas em nó de madeira, que variam de 5 a $7 \mathrm{~cm}$. Segundo (Etzel, 1979, 116), encontram-se nestas últimas, orifícios para passar o cordão que permitia carregá-las no pescoço.

\section{Intervenções nas imagens nos séculos XVIII a XX}

Podemos conhecer em transcrições de documentos originais, nas publicações de Judith Martins (1974), Marieta Alves (1976), e Vera Aciolli (2008), referências às intervenções para a conservação de esculturas religiosas, o que, em geral, era feito antecedendo as festas de cada santo e, especialmente, nas Semanas Santas, quando iriam sair em procissões. Encontram-se, em Judith Martins, expressões como "a Imagem ser concertada", "concerto de um crucifixo", "por fazer os dedos da image", "reparar a Imagem". As imagens de vestir recebiam sempre roupas novas, mas as esculturas de vulto originais eram também "renovadas", algumas vezes com policromia de boa qualidade, quando feitas nos século XVIII e XIX.

Encontramos repinturas, feitas mais recentemente, de muito má qualidade, executadas com tintas comerciais e purpurina encobrindo pinturas sobre folhas de ouro de excelente acabamento, com técnicas muito bem executadas, em esgrafito, punções e pinturas a pincel. São Simão Stock e São João da Cruz [figura 6], do mestre Aleijadinho, tiveram os resplendores, muito bem entalhados em madeira e totalmente revestidos com folhas de prata, integralmente cobertos por purpurina prateada, e parte das capas de ambos repintadas com tintas comerciais Todas essas intervenções foram feitas, provavelmente, com intenção de "embelezar". Muitas pinturas originais, de excelente qualidade, foram também raspadas e tornadas ilegíveis por mão ditas "muito habilidosas", que as prejudicaram e descaracterizaram, tornando, algumas vezes, impossível sua leitura ou recuperação.

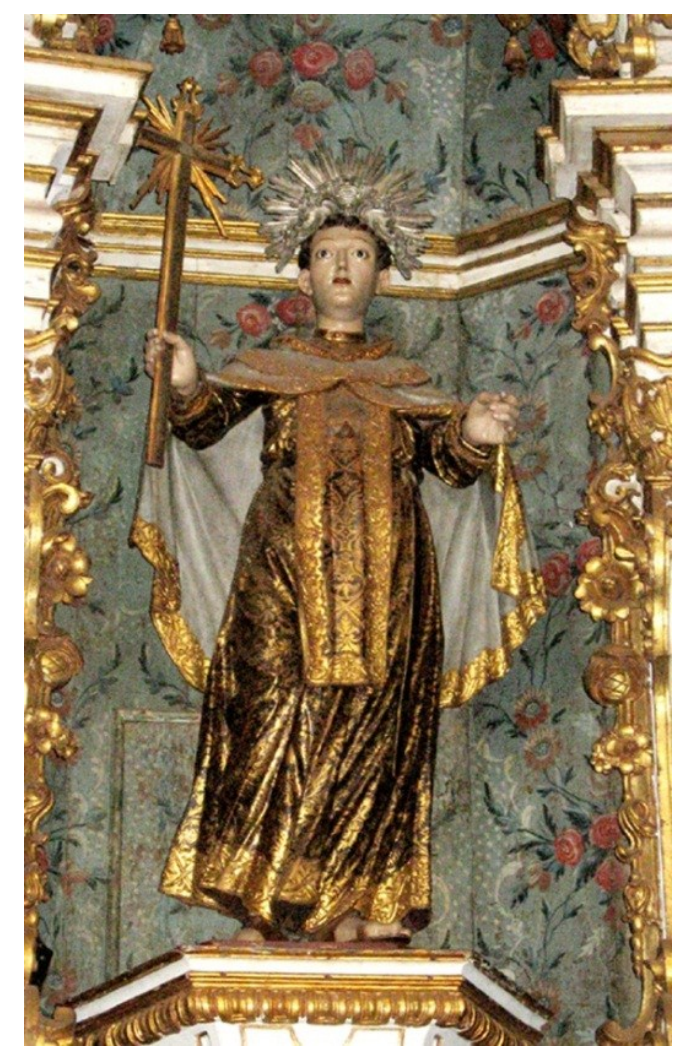

Figura 6. São João da Crur: $160 \mathrm{~cm}$. Antônio Francisco Lisboa, o Aleijadinho, 1778. Igreja de Nossa Senhora do Carmo, Sabará Minas Gerais. Foto: Beatriz Coelho. 
Após a criação do então Serviço do Patrimônio Histórico e Artístico Nacional, em 1937, começou no Brasil o que hoje chamamos de "fase heróica", em que se deveria identificar e registrar com fotografias e textos os monumentos que deveriam ir para o "Livro de Tombo", no qual estariam os bens a serem preservados. "Fase heróica" porque, naquele tempo, o Patrimônio dispunha de muito poucas pessoas, ainda não havia boas estradas, e os meios de transporte eram os cavalos, nos quais eram percorridas grandes distâncias para executar tal tarefa. Por esses motivos, a atenção foi dada aos monumentos, especialmente os da religião católica, os que faziam parte do sistema de governo, e as fortalezas que tinham sido usadas para a defesa do local. Nesse momento, foram registrados também os retábulos existentes nos monumentos religiosos. Os bens móveis só começaram a ser inventariados a partir de 1986, uma tarefa imensa, que foi executada pelo Iphan com o patrocínio da fundação Vitae - Apoio à Cultura, à Educação e ao Desenvolvimento Social. Com o Inventário de Bens Móveis e Integrados, que ainda está em andamento em alguns lugares, foi possível avaliar a quantidade e a qualidade dos acervos dos monumentos tombados anteriormente, incluindo-se o da escultura religiosa do nosso país, ficando mais fácil também a identificação das obras em caso de furto.

\section{A restauração com novos critérios e bases científicas}

Em 1939, o artista plástico Edson Motta obteve bolsa de viagem ao exterior, como prêmio do Salão Nacional de Belas Artes, oportunidade na qual esteve em Portugal, Espanha e Itália, estudando aspectos técnicos da pintura. Em 1944, foi convidado por Rodrigo Mello Franco de Andrade, diretor do SPHAN, para ser o principal conservador e para organizar o Setor de Conservação e Restauração de Obras de Arte, que funcionaria como ateliê central, na cidade do Rio de Janeiro. Em 1946, ele viajou para os Estados Unidos, com uma bolsa da Fundação Rockfeller, quando fez estágio de dois anos no Fogg Art Museum, em Boston, sob orientação de Rutherford Gettens, George Stout e Morton Bradley Júnior. Na volta, trouxe novos critérios de respeito ao original e técnicas de restauração mais aprimoradas, sendo, a partir desse momento, o mais importante incentivador e formador de profissionais da preservação do patrimônio móvel e integrado no Brasil. Em 1953, como professor da Escola de Belas Artes da Universidade do Rio de Janeiro e restaurador do Iphan, criou duas disciplinas no curso de Belas Artes, destinado à formação de artistas plásticos: Restauração de Pinturas e Restauração de Obras sobre Papel. Logo após, em Salvador, na Universidade Federal da Bahia (UFBA), seu amigo, o professor e também pintor João José Rescala criou outras duas disciplinas: Restauração I (Restauração de pinturas) e Restauração II (Restauração de esculturas). Essas universidades foram pioneiras, portanto, na introdução de disciplinas de restauração de obras de arte em cursos universitários no Brasil. O objetivo não era formar restauradores, mas fornecer conhecimentos de restauração aos que buscavam formação artística. Nessa época, a maioria dos profissionais que trabalhavam em restauração de pinturas, esculturas, obras de talha, documentos e obras sobre papel foi preparada nessas disciplinas da Escola de Belas Artes do Rio ou da Bahia e em estágios no ateliê do Iphan do Rio de Janeiro. Alguns frequentaram os dois ambientes, no Rio e na Bahia.

Em Minas Gerais, mais precisamente em Ouro Preto, em 1970, outro importante e conhecido restaurador brasileiro, Jair Afonso Inácio, que iniciara o seu aprendizado com o professor Edson Motta, tendo feito, em 1961, estágio no Institut Royal du Patrimoyne Artistique (IRPA), em Bruxelas na Bélgica, começou, na Fundação de Arte de Ouro Preto, um curso para a preparação de restauradores, no qual trabalhou até sua morte, em 1982. Esse curso não pertencia a uma universidade, mas preparou muitos restauradores que prestaram, e ainda prestam, seus serviços, não só em Ouro Preto, mas em outras cidades do país. No Nordeste, especialmente em Pernambuco, Paraíba e Alagoas, José Ferrão Castelo Branco foi orientador de muitos restauradores, recebendo sempre, segundo relatou à autora deste artigo, orientação e sugestões do professor Edson Motta. Um pouco depois, Lúcia Carneiro, de Recife, foi para o México, onde fez o curso de restauração no Centro de Churubusco e, na volta, orientou pessoas que, na época, eram estudantes da Escola de Arquitetura e Belas Artes da Universidade Federal de Pernambuco. 


\section{A importância do curso de especialização da Escola de Belas Artes da Universidade Federal de Minas Gerais (UFMG)}

Em 1976 a autora desse artigo, como diretora em exercício da Escola de Belas Artes da Universidade Federal de Minas Gerais, recebeu um ofício do então reitor, professor Eduardo Osório Cisalpino, solicitando que fossem tomadas providências junto ao Instituto do Patrimônio Histórico e Artístico Nacional para a restauração de pinturas sobre tela que pertenciam à Escola de Música. Essas pinturas haviam ficado "desaparecidas" por alguns anos. Eram 13 telas, as quais totalizavam $39 \mathrm{~m}^{2}$, que haviam sido reencontradas em um depósito da Universidade. O diretor do Iphan em Minas Gerais na época, Dr. Roberto Machado Lacerda, enviou um técnico para verificar o estado das obras e fazer um levantamento do material que seria necessário para a restauração. Esse restauro, coordenado por mim e com a participação de outros professores, levou dois anos para ser terminado e foi o começo dos trabalhos de conservação e restauração na Escola de Belas Artes.

Em 1977, encaminhei um projeto de curso para a formação de restauradores, que, após ser examinado pelo Iphan e aprovado, foi financiado pela então Secretaria de Planejamento da Presidência da República, hoje Ministério do Planejamento, através do Programa de Cidades Históricas, extinto em 1990. Esse curso de especialização em Conservação e Restauração de Bens Culturais Móveis tinha por objetivo dar formação adequada a profissionais, para a restauração de pinturas, esculturas em madeira, obras e documentos sobre papel. Poderiam ser admitidas, inicialmente, apenas pessoas que trabalhassem em instituições de preservação do patrimônio no Brasil e, preferencialmente, que tivessem concluído um curso universitário. Cursos como esse correspondem, em nosso país, à especialização, ou pós-graduação lato sensu. No primeiro curso havia apenas um estudante de outro estado, mas logo chegaram solicitações para que houvesse outro curso, permitindo que profissionais de outros estados pudessem participar. Assim, a formação de restauradores com um certificado universitário manteve-se durante 30 anos, formando conservadores restauradores para quase todos os estados brasileiros e também para alguns países da América Latina, estes últimos com bolsa do Programa das Nações Unidas para o Desenvolvimento (PNUD/Unesco). Desse curso participaram, como professores, importantes restauradores do Brasil, como João José Rescala, Jair Inácio, Ado Malagoli, Maria Luíza Guimarães, e Geraldo Francisco Xavier Filho, mais conhecido como Ládio. Participaram em outros anos vindos do exterior: Josep Maria Xarrié i Rovira (Espanha), Martha Plazas de Fontana (Colômbia), Guilhermo Joiko (Chile), Maria Fernanda Vianna (Portugal) e Gaël de Guichen (ICCROM/Itália). Esse curso constava de matérias teóricas e práticas, entre as principais, Restauração de Esculturas, que se constituía, exclusivamente, de imagens devocionais em madeira policromada. Os professores dessa matéria foram Jair Afonso Inácio e Geraldo Francisco Xavier Filho. A parte teórica sobre a Imaginária Religiosa Brasileira, foi ministrada pelo museólogo Orlandino Seitas Fernandes e Iconografia Religiosa, com a museóloga, Valdete Celino Paranhos.

\section{Criação do Centro de Conservação e Restauração (Cecor)}

Em 1979 começou, na Escola de Belas Artes da Universidade Federal de Minas Gerais (UFMG), a construção do Centro de Conservação e Restauração de Bens Culturais Móveis, o Cecor. Essa construção foi possível graças ao financiamento da Secretaria de Cultura do então Ministério da Educação e Cultura. O prédio tinha, inicialmente, $700 \mathrm{~m}^{2}$, com ateliês de pintura, escultura e obras sobre papel, laboratório de química, estúdio fotográfico, diretoria e secretaria para abrigar o curso de especialização e professores ou funcionários que viessem ali trabalhar. $\mathrm{O}$ Cecor foi inaugurado solenemente no dia 5 de setembro de 1980, pelo reitor da Universidade, Professor Celso Pinheiro, como parte integrante do 530 aniversário de fundação da UFMG.

O Cecor, além de abrigar o curso durante esses 31 anos, vem desempenhando papel importante não só na formação de conservadores/restauradores, mas também no desenvolvimento de pesquisas e na prestação de serviços para instituições e particulares, entre eles restauração dos retábulos de Aleijadinho, na Matriz do Pilar em Nova Lima, situada na região metropolitana de Belo Horizonte, a imagem de Nossa Senhora 
da Piedade a ele atribuída [figura 7 e 8], da pintura de Manoel da Costa Ataíde no forro da Igreja de São Francisco de Assis, em Ouro Preto, da caixa do órgão da Igreja de Nossa Senhora da Assunção, Catedral de Mariana, das pinturas murais da igreja matriz da cidade de Divinópolis, de pinturas murais e sobre tela do Grande Hotel de Araxá e, atualmente, do museu Casa de Padre Toledo, em Tiradentes.

Em 1989, foi realizado no Cecor o Seminario Taller de Actualización para América Latina: Conservación de Escultura Policromada, para profissionais experientes da América Latina, resultante de um convênio entre o Getty Conservation Institute, o Proyecto Regional de Patrimonio Cultural y Desarrollo (PNUD/UNESCO) e a Universidade Federal de Minas Gerais. Como docentes desse curso, participaram experientes professores e restauradores da Europa, Estados Unidos e Brasil: Agnes Gräfin Ballestrem, Brian Considine, JeanAlbert Glatigny, Bettina Raphael e Monique Pequignau, substituindo Myriam Seck-Dewaide, que não pôde comparecer; do Brasil, Adair Evangelista Marques, Antônio Carlos Queiroz Mascarenhas e Beatriz Coelho. Esse curso trouxe novos critérios e nova metodologia para o estudo de uma escultura, informações e exercícios práticos sobre técnicas e materiais a serem empregados nas intervenções necessárias.

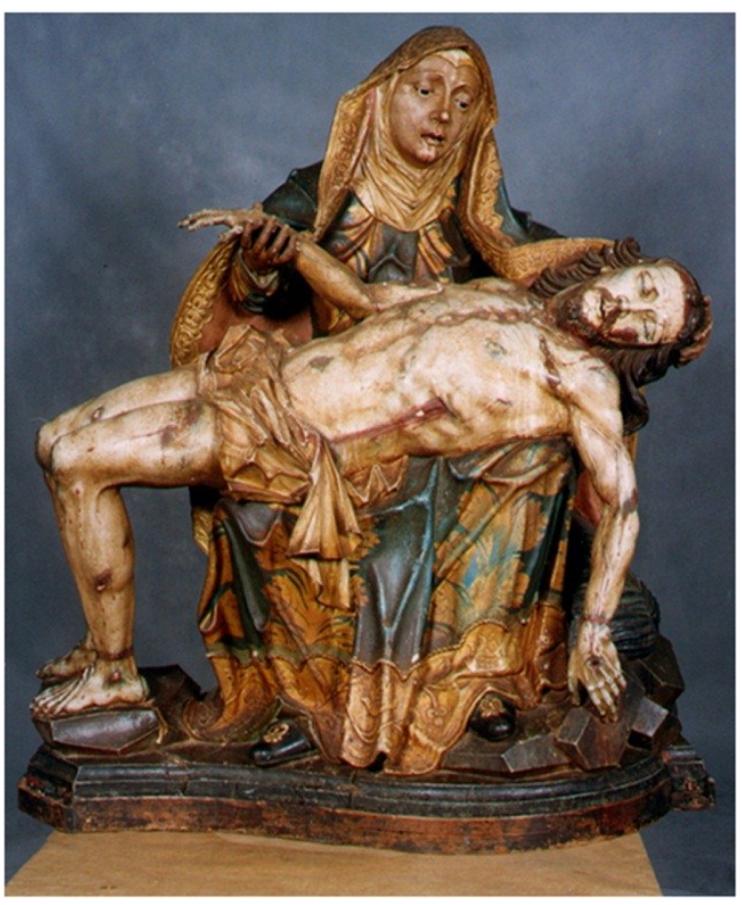

Figura 7. Nossa Senhora da Piedade. Aleijadinho (Atribuição). $112 \mathrm{~cm}$. C. 1784. Antes da restauração no

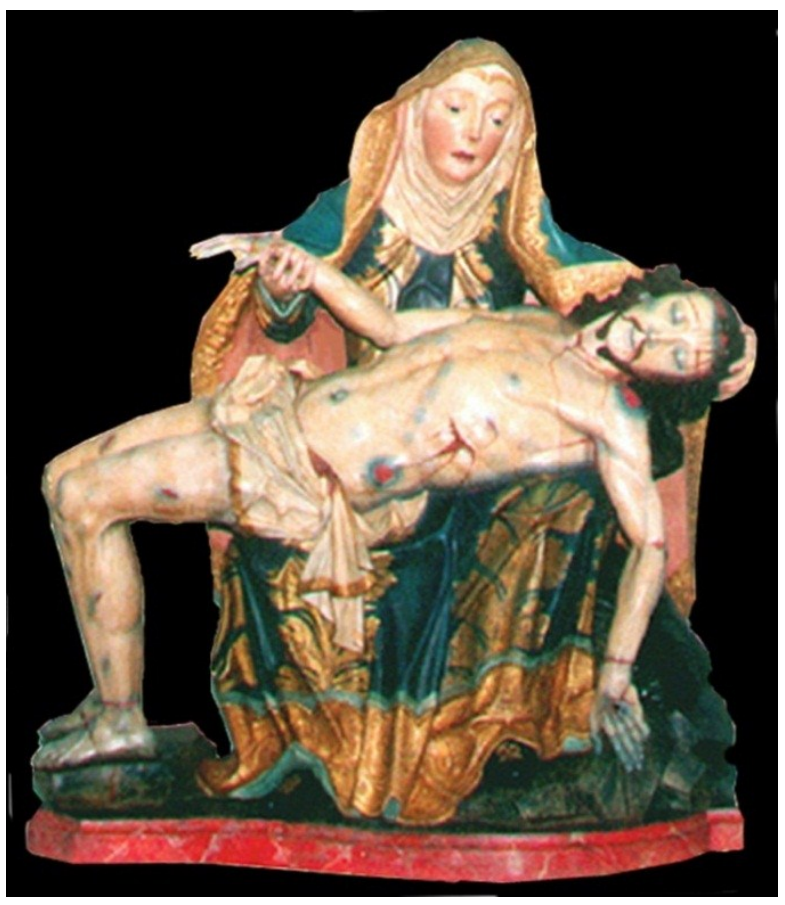

Figura 8. Nossa Senhora da Piedade. Depois da restauração no Cecor. Foto: Beatriz Coelho

\section{Cursos em Minas e outros estados}

Em 2008, começou a funcionar na mesma Escola o curso em nível de graduação, sendo o primeiro no Brasil a formar bacharéis em Conservação e Restauração de Bens Culturais Móveis. Nesse curso, uma das áreas mais importantes é a de conservação e restauração de escultura em madeira policromada, ou seja, de imaginária devocional, uma das mais importantes expressões do patrimônio brasileiro do período colonial. Com o início do curso de graduação, está sendo repensado o curso no nível de especialização, que deverá voltar a funcionar, porém com características diferentes dos anteriores.

Além do curso de graduação da UFMG, funcionam atualmente, no Brasil, vários cursos, que têm objetivos e níveis diversos. Envolvendo a conservação e restauração de escultura, temos: no Rio Grande 
do Sul, na Universidade Federal de Pelotas, Conservação e Restauração de Bens Culturais; em Brasília, curso Superior de Tecnologia em Conservação e Restauro; em São Paulo, o curso tecnológico (superior de curta duração) de Conservação e Restauro, na Pontifícia Universidade Católica; cursos técnicos e póstécnicos em Conservação e Restauração, no Centro Técnico Templo da Arte; em Minas Gerais, além do curso da Escola de Belas Artes, funciona há muitos anos o de Conservação e Restauração de Obras de Arte, oferecido pela Fundação de Arte de Ouro Preto (FAOP), criado por Jair Afonso Inácio na década de 1970 como curso livre, passando a curso técnico a partir de 2002. Outros cursos estão para ser iniciados em Salvador e no Rio de Janeiro.

\section{A Associação Nacional de Conservadores e Restauradores de Bens Culturais}

Em 1980 foi criada, por um grupo de professores universitários e profissionais da restauração, no Rio de Janeiro, a Associação de Conservadores e Restauradores de Bens Culturais (Abracor), que passou a ter uma enorme influência na área de restauração, pois reúne conservadores restauradores de todo o Brasil, organizando congressos e seminários, publicando artigos e fornecendo informações sobre o tema. A Abracor já realizou 13 Congressos, reunindo profissionais da restauração e da conservação não só do Brasil, mas também do exterior. A partir da criação da Abracor, os profissionais da preservação do patrimônio brasileiro se conhecem, trocam informações, apresentam e podem publicar os resultados de seus trabalhos. Há alguns anos, a Abracor vem lutando para que seja reconhecida e regulamentada a profissão no Brasil. No momento, o projeto de lei encontra-se em discussão no Senado Federal.

\section{Criação do Centro de Estudos da Imaginária Brasileira (Ceib)}

Em 1995, a professora e historiadora de arte, Myriam Andrade Ribeiro de Oliveira, fez uma reunião no Rio de Janeiro com a autora deste artigo, e informou que, em suas andanças pelo Brasil estudando a arte colonial brasileira, havia chegado à conclusão de que a imaginária religiosa era a expressão mais autêntica e expressiva do nosso povo, mas que havia poucos estudos sistemáticos sobre o assunto. Sabendo que vinha eu, há alguns anos, desenvolvendo pesquisas sobre a imaginária mineira, queria convidar-me para criarmos uma associação que se destinasse a estimular os estudos e a publicação dos resultados de trabalhos e pesquisas sobre o tema. A criação da associação foi feita em 29 de outubro de 1996, em reunião com historiadores de arte e conservadores, restauradores, quando a idéia foi recebida com entusiasmo por todos. Desde então, o Centro de Estudos da Imaginária Brasileira (Ceib), que funciona na Escola de Belas Artes da UFMG por especial atenção das diversas diretorias, vem desenvolvendo um bom trabalho e cumprindo seus objetivos, que são: reunir os estudiosos da imaginária brasileira e de assuntos correlatos, como a pintura e a talha; estimular o desenvolvimento de estudos e pesquisas sobre as imagens brasileiras e sua conservação; promover o intercâmbio com instituições afins; e divulgar os resultados desses estudos no Brasil e no exterior. Para isso, o Ceib mantém duas publicações: o Boletim do Ceib, sempre com trabalhos inéditos, que começou a ser publicado em 1996 e está no número 49, e a revista Imagem Brasileira, que publica artigos e conferências apresentados nos congressos do Ceib. Essas publicações são distribuídas gratuitamente aos associados e a bibliotecas de instituições e paróquias do Brasil e do exterior. O Centro de Estudos já realizou seis congressos, quatro em Minas Gerais, um em Vitória, capital do estado do Espírito Santo, outro no Rio de Janeiro, e o próximo acontecerá no mês de outubro de 2011, em Ouro Preto, Minas Gerais.

\section{Brasil 500 anos /Mostra do Redescobrimento.}

No ano 2000, no Parque Ibirapuera, em São Paulo, houve uma mega-exposição sobre a arte brasileira, comemorativa dos 500 anos do descobrimento, inaugurada e encerrada em duas datas histórias: em 21 de abril (descobrimento) 7 de setembro (proclamação da independência). Essa exposição abrangia peças arqueológicas, objetos e documentos trazidos de Portugal, artes indígenas, afro-brasileira, dos estrangeiros que viveram no Brasil, arte do inconsciente - feita por internos em sanatórios - arte popular, arte barroca, 
século XIX, moderna e contemporânea. Em todos os setores a exposição fugia do habitual, com as peças sendo expostas em cenários criados por conhecidos cenógrafos, iluminadores, etc. Esse fato foi criticado por muitas pessoas, jornalistas e profissionais de vários setores da opinião pública, mas isso fez com que a exposição tocasse os sentimentos e a alma do povo brasileiro, que acorreu em massa para ver os objetos expostos. Do barroco foi curadora a historiadora de arte Myriam Andrade Ribeiro de Oliveira, que decidiu dedicar todo o setor a um único segmento: o da imaginária devocional. Estavam expostas imagens trazidas de Portugal no início da colonização, ou feitas por portugueses no Brasil, de conventos beneditinos, franciscanos, carmelitas e dominicanos, confeccionadas por leigos em várias partes do Brasil, indo de Belém do Pará às Missões no Sul do país. A cenografia ficou a cargo da cenógrafa Bia Lessa, que distribuiu no amplo espaço destinado ao barroco, conjuntos de flores em papel crepom, amarelas e roxas, confeccionadas, especialmente, por prisioneiros de uma grande prisão de São Paulo, a Carandiru, hoje demolida [Figura 9]. Havia uma trilha sonora que ia desde músicas indígenas - no setor das Missões - até cânticos usados em igrejas e procissões. Esse setor foi o único a contar com um ateliê de conservação das obras expostas e que podia ser visto pelo público visitante. Foi o setor da exposição que mais emocionou os visitantes. Alguns saíam com lágrimas nos olhos, tão tocados pelas imagens, cenários e sons. Depois desse momento, certamente a escultura religiosa brasileira ficou mais conhecida e valorizada.

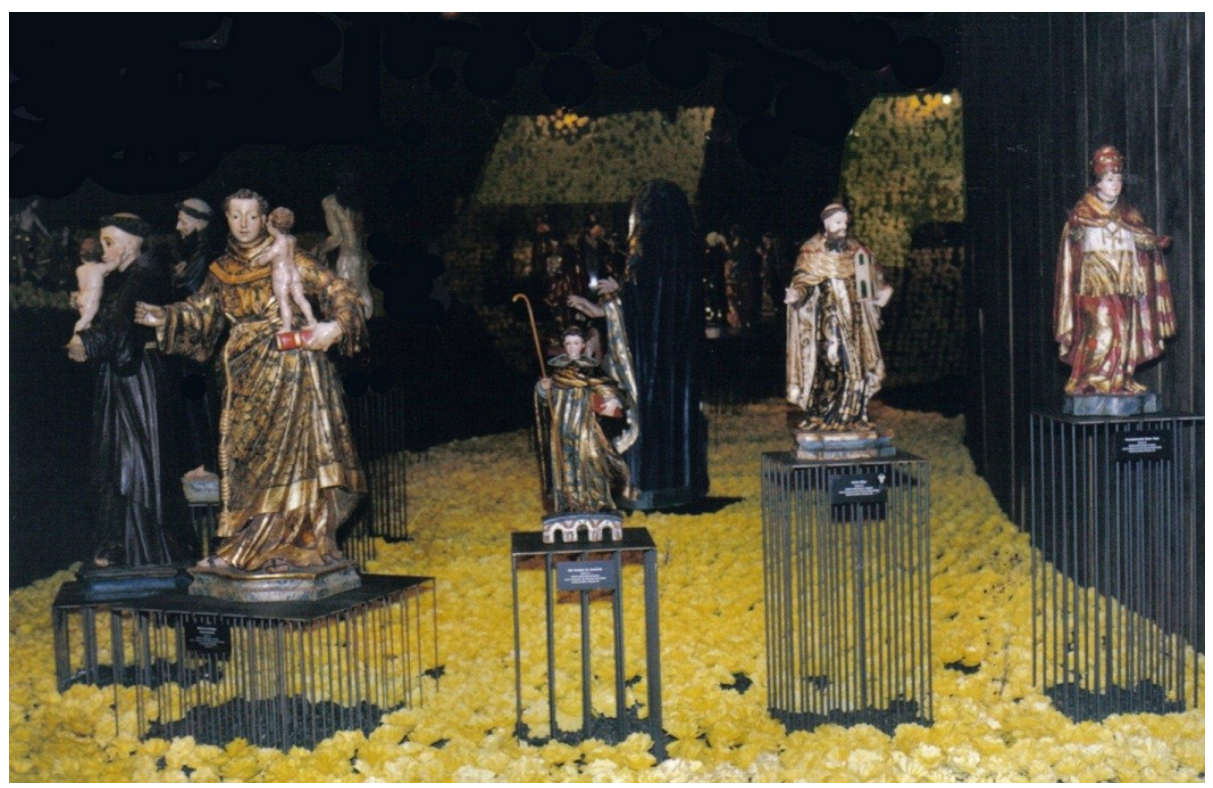

Figura 9. Vista parcial do Módulo Barroco, da Mostra do Redescobrimento. São Paulo - São Paulo, 2000. Foto: Beatriz Coelho.

\section{Situação atual da conservação do patrimônio escultórico no Brasil}

O patrimônio escultórico brasileiro dos séculos, XVII, XVIII e XIX é constituído principalmente, por imaginária religiosa, consequência da religiosidade que os portugueses trouxeram e propagaram no Brasil colônia. Os suportes mais empregados foram o barro, a madeira, o marfim (muitas imagens desse material vieram das colônias portuguesas na China e no Japão), a pedra e alguns outros materiais, como papel e tecido encolado. Os principais problemas encontrados são o ataque de insetos, fungos e a grande quantidade de pinturas sobrepostas. Essas pinturas não deterioram as esculturas, mas as descaracterizam inteiramente, encobrindo todo o trabalho original com policromias de má qualidade. Apesar de vários cursos hoje em funcionamento em alguns estados brasileiros, convivem, no Brasil, duas linhas de intervenções: uma, de pessoas sem formação alguma, possuidoras de alguma habilidade, mas que desconhecem completamente os critérios e técnicas adotados atualmente em muitos países, de respeito ao original e de mínima intervenção; outro, de pessoas com curso universitário em diversas áreas, como artes 
plásticas, história, química, que estudaram no Cecor ou em outras instituições, e têm formação, a nosso ver adequada, com critérios e técnicas corretos e adotados mundialmente, preservando, desde que possível, todas as características originais, ou históricas de importância, encontradas em cada obra. As intervenções nas imagens seguem também essas duas linhas, mas acreditamos e observamos que está crescendo o número de pessoal qualificado. Alguns especialistas continuam seus estudos, obtendo, no Brasil ou no exterior, títulos de Mestre e de Doutor, na conservação ou em áreas afins.

Brevemente começarão a receber seus diplomas os que ingressaram ou estão ingressando nos cursos de graduação das várias universidades brasileiras, embora seja um pouco preocupante o surgimento de muitos cursos novos. Na graduação, passarão a funcionar de seis a oito semestres simultaneamente, com turmas de 20 a 30 alunos. Sabemos que cursos para a formação de conservadores restauradores precisam ter obras originais e únicas para serem estudadas e trabalhadas, materiais de primeira qualidade para as intervenções necessárias, bibliotecas e professores bem preparados. Portanto, fica a indagação: os novos cursos disporão de tudo isso?

Para o desenvolvimento dos estudos e conhecimentos sobre a escultura religiosa no Brasil, foi essencial a criação e o funcionamento do Centro de Estudos da Imaginária Brasileira, que, com suas atividades reúne, atualmente, 158 associados, a maior parte de diversos estados brasileiros, mas com alguns sócios em outros países, como Portugal, Argentina e Bélgica. São professores universitários, estudantes e profissionais, de diversas áreas do conhecimento, como história da arte, artes plásticas, conservação e restauração, arquitetura e museologia, cada um enfocando, de maneira especial, aspectos como história, função social, iconografia, autoria e atribuições, materiais e técnicas, preservação, conservação e restauração. Esses associados se encontram nos congressos, e publicam ou tomam conhecimento de pesquisas e trabalhos realizados através das publicações do Ceib. Hoje, quase todos os artigos sobre imagens religiosas no Brasil trazem referências a trabalhos publicados no Boletim do Ceib ou na revista Imagem Brasileira. Entre os associados estão doutores, mestres, especialistas e estudantes de pósgraduação ou, mais recentemente, de graduação. Estamos certos de que o papel desempenhado pelo Ceib estimulou esses estudos e fez crescer os conhecimentos e a valorização da imaginária religiosa no Brasil e os cuidados e critérios para sua preservação.

\section{Notas}

[1] Clarival do Prado Valadares: Prefácio do livro de Dom Clemente sobre os dois escultores [...] "o Menino Jesus, cuja atitude é toda oriental, lembrando um pequeno Buda da Índia.” A meu ver, essa semelhança aparece também em quase todos os bustos relicários de frei Agostinho da Piedade.

[2] Dom Clemente considera que essa frase (em português: Tende Piedade de mim), foi outra maneira de frei Agostinho registrar seu próprio nome PIEDADE (grifo nosso).

[3] Essas imagens foram repintadas, mas a repintura foi removida da última restauração, feita em 2005.

[4] Segundo Myriam Ribeiro, essas duas imagens não combinam com o estilo de frei Domingos da Conceição.

\section{Bibliografia}

ALVES, M. (1976). Dicionário de artistas e artifices na Babia. Salvador: Universidade Federal da Bahia.

ACIOLI, V. L. C. (2008). Identidade da beleza: Dicionário de artistas e artífices do século XVI ao XIX em Pernambuco. Recife: Fundação Joaquim Nabuco / Massangana.

BAZIN, G. (Sd.) Aleijadinho e a escultura barroca no Brasil. 2 ed. Revisada e atualizada. Trad. Mariza Murray. Rio de Janeiro: Record,. 
COELHO, B. (2005). "Materiais, técnicas e conservação". En: COELHO, B. (Org.). Devoção e arte. Imaginária religiosa em Minas Gerais. São Paulo: Edusp, 233-245.

COLNAGO FILHO, A. (2007). "Símbolo de fé no Espírito Santo”. Boletim do Ceib, Ceib: v.11, 38, novembro: 01-05.

ETZEL, Eduardo (1979). A imagem sacra brasileira. São Paulo: Melhoramentos / Editora da Universidade de São Paulo.

MARTINS, J. (1974). Dicionário de artistas e artífices dos séculos XVIII e XIX em Minas Gerais. Rio de Janeiro: Ministério da Educação e Cultura / Departamento de Assuntos Culturais.

OLIVEIRA, M. A. R. (2000). A imagem religiosa no Brasil. Mostra do Redescobrimento/Arte Barroca. São Paulo: Fundação Bienal de São Pau, 37-79.

OLIVEIRA, M. A. R.; SANTOS FILHO, O. R.; SANTOS, A. F. B. (2002). O Aleijadinho e sua oficina: Catálogo das esculturas devocionais. Rio de Janeiro: Capivara.

QUITES, Ma R. E (2006). Imagem de vestir: revisão de conceitos através de estudo comparativo entre as ordens terceiras franciscanas no Brasil.. Campinas. Tese de doutorado apresentada à Universidade Estadual de Campinas. Orientador: Luciano Migliaccio.

SILVA-NIGRA, D. C. M. (1950). Frei Domingos da Conceição - O escultor seiscentista do Rio de Janeiro. Salvador: Tipografia Beneditina.

SILVA-NIGRA, D. C. M. (1971). Os dois escultores, frei Agostinho da Piedade, frei Agostinho de Jesus e o arquiteto frei Macário de São João. Salvador: Universidade Federal da Bahia.

SALGUEIRO, H. A.(1983). A singularidade da obra de Veiga Valle. Goiânia: Universidade Católica de Goiás.

SOUZA, J. V. A. (2007). "A condição de "irmão converso" no mosteiro de São Bento do Rio de Janeiro: o caso do escultor frei Domingos da Conceição 1643-1718”. Ceib: Boletim Do Ceib, v.11, n.17.

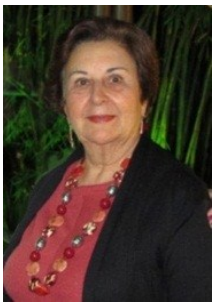

Beatriz Ramos de Vasconcelos Coelho

Rua Leopoldino dos Passos, 278

31.275-010, Belo Horizonte, MG, Brasil

beatrizrvcoelho@gmail.com

Nace en Brasil. Profesora, desde 1972, y Directora, entre 1974 y 1981, de la Escuela de Bellas Artes de la Universidad de Minas Gerais, Belo Horizonte, Brasil. Fundadora y Directora del Centro de conservación y Restauración de esa casa de estudios. Profesora de restauración de escultura policromada y pintura de caballete en el Curso de Especialización en Conservación y Restauración de Bienes Culturales Muebles de la Escuela de Bellas Artes, UFMG, desde 1982. Coordinadora del Seminario de Conservación de Pintura Policromada en el Getty Conservation Institute, Proyecto Regional del Patrimonio Cultural y Desarrollo, UFMG, Belo Horizonte, en 1989. Ha publicado el trabajo "A contribution to the study of Aleijadinho, the most important sculptor of colonial Brazil" en: Conservation of the Iberian and Latin American Cultural Heritage, IIC, Londres, 1992. Ha participado en seminarios internacionales en La Habana, Lima, Madrid y Caracas. Coordinadora del libro Devoção e Arte: imaginária religiosa em Minas Gerais. É presidente do Centro de Estudos da Imaginária Brasileira (Ceib) desde 1998. 